J Adolesc Health. 2020 June ; 66(6): 691-698. doi:10.1016/j.jadohealth.2019.12.010.

\title{
Transgender Youth's Disclosure of Gender Identity to Providers Outside of Specialized Gender Centers
}

\author{
Gina M. Sequeira, MD, MS ${ }^{\star}{ }^{\dagger}$, Kristin N. Ray, MD, MS $^{\dagger}$, Elizabeth Miller, MD, PhD $^{\star}{ }^{\dagger}$, Robert \\ W. S. Coulter, PhD, MPH ${ }^{\ddagger}$ \\ *UPMC Children's Hospital of Pittsburgh Pittsburgh, PA, USA 15213 \\ †Department of Pediatrics University of Pittsburgh School of Medicine Pittsburgh, PA 15224 \\ ¥School of Public Health University of Pittsburgh Pittsburgh, PA, USA 15213
}

\begin{abstract}
Purpose-Transgender youth face significant health disparities and multiple barriers to receiving quality healthcare. Gender identity disclosure to healthcare providers (HCPs) is an important step in creating affirming relationships for transgender youth. The objectives of this study were to: (1) determine the prevalence of voluntary disclosure and intentional avoidance to HCPs outside of gender clinics; (2) identify factors associated with voluntary disclosure and intentional avoidance; and (3) elucidate strategies to increase comfort with disclosure.
\end{abstract}

Methods-A cross-sectional survey was administered to transgender youth ages 12-26. Bivariate analyses were conducted using chi-square or Fisher's exact tests. Two logistic regression models for each outcome variable were used to examine factors associated with voluntary disclosure and intentional avoidance.

Results-Two-thirds (65\%) of youth ( $\mathrm{N}=153)$ identified as transmasculine and $57 \%$ were under 18. Three-quarters (78\%) had voluntarily disclosed their gender identity to a HCP outside of gender clinic, while $46 \%$ had intentionally avoided disclosure. Odds of ever having disclosed were lower for participants 18 and over ( $\mathrm{OR}=0.33 ; 95 \% \mathrm{CI}$ : $0.11,0.98)$, those out to fewer people $(\mathrm{OR}=0.12 ; 95 \% \mathrm{CI}: 0.02,0.81)$ and out for less than 1 year $(\mathrm{OR}=0.03 ; 95 \% \mathrm{CI}: 0.004,0.31)$. Odds of intentional avoidance were lower among youth with higher perceived parental support $(\mathrm{OR}=0.83$; 95\% CI: $0.70-0.98)$.

Conclusion-A majority of transgender youth reported having voluntarily disclosed their gender identity to a HCP outside of gender clinic, but almost half reported having intentionally avoided disclosure when they felt it was important. Parental support may play a protective role in mitigating avoidance.

Corresponding author: Gina M Sequeira, MD, MS, 120 Lytton Ave, Pittsburgh, PA, USA 15213 gina.sequeira@ chp.edu phone: (412) 692-6677 fax: (412) 692-8584

Publisher's Disclaimer: This is a PDF file of an unedited manuscript that has been accepted for publication. As a service to our customers we are providing this early version of the manuscript. The manuscript will undergo copyediting, typesetting, and review of the resulting proof before it is published in its final form. Please note that during the production process errors may be discovered which could affect the content, and all legal disclaimers that apply to the journal pertain. 


\section{Keywords}

transgender youth; gender identity; voluntary disclosure; intentional avoidance

\section{Introduction}

Transgender youth often face significant societal stigma and discrimination in addition to multiple barriers to receiving quality healthcare. ${ }^{1-5}$ It is likely that a combination of these factors contributes to the development of the significant health disparities ${ }^{6-12}$ and lower rates of healthcare utilization seen in this population. ${ }^{13,14}$ Access to affirming environments ${ }^{15,16}$ and gender affirming medical care ${ }^{17-19}$ reduces these alarming health outcomes, but a limited number of transgender health specialists are available across the US. ${ }^{1,7,20-22}$ Voluntary gender identity disclosure to healthcare providers (HCP's) outside of specialized gender clinics is a crucial step in developing gender affirming relationships with a HCP and may facilitate access to transgender health specialists. ${ }^{23,24}$ More broadly, voluntary disclosure of gender identity may be needed to maximize effectiveness, appropriateness, or safety of care (e.g., appropriate radiologic procedures, appropriate sexual health screening).

No prior studies have investigated the prevalence of voluntary disclosure- or its corollary, intentional avoidance- among transgender youth. Nor have studies explored the personal and system-level factors that influence youth comfort with gender identity disclosure in the healthcare setting. Prior studies have shown the majority of transgender adults feel identity disclosure to healthcare providers is important ${ }^{23,25-30}$ and suggest that disclosure may differ based on gender identity, with binary transgender adults more likely to disclose (84\%) than those who identify as nonbinary (52\%). ${ }^{26}$ Additionally, one-third (31\%) of transgender adults indicated they had not disclosed their gender identity to any of their current healthcare providers (HCPs). ${ }^{26}$ Unfortunately, no similar studies have been conducted in youth, but prior research investigating disclosure preferences of lesbian, gay and bisexual (LGB) youth suggests that despite feeling it is important that their HCP know their sexual orientation, most had not disclosed. ${ }^{31}$ LGB youth suggested providers initiate conversations about sexual orientation during clinical visits and provide opportunities to speak with youth confidentially to increase comfort with disclosure. Focused examination of these same questions among transgender youth is necessary to inform the creation of more welcoming healthcare spaces to support voluntary disclosure, reduce intentional avoidance and ultimately mitigate health disparities.

Thus, there is a knowledge gap regarding transgender youth's experience with voluntary disclosure and intentional avoidance in health care settings, which is crucial to address to develop gender affirming environments for transgender youth. We aimed to fill this knowledge gap by conducting a cross-sectional survey with transgender youth about their health care experiences. The objectives of this study were threefold: (1) to determine the prevalence of voluntary gender identity disclosure and intentional avoidance in interactions with HCPs outside of specialized gender centers; (2) to identify factors associated with voluntary disclosure and intentional avoidance; and (3) to elucidate strategies to increase 
comfort with voluntary disclosure, thereby leveraging youth perspectives to create more inclusive health systems.

\section{Methods}

\section{Study Design and Population}

The study was conducted using a cross-sectional survey administered via electronic tablet. Transgender youth ages 12-26 were recruited from a multidisciplinary gender clinic in Southwestern Pennsylvania between July and November 2018. The first author reviewed the electronic health record of upcoming clinic schedules to identify potential study participants. Patients were approached by either their medical provider or a member of the research staff to introduce the study during a regularly scheduled clinic visit. With informed consent obtained, interested youth were screened based on their response to the following question 'How do you describe your gender identity?'. Youth who identified their gender identity as only cisgender were excluded. In total, 211 youth were approached to participate, and 6 of these individuals were excluded due to identification as only cisgender. Of the remaining 205 participants, 204 completed the survey (99.5\% participation rate). Approval, including a waiver of parental consent for participants younger than 18 , was obtained from the Institutional Review Board (IRB).

\section{Measures}

The survey consisted of 78 items, with this analysis focusing on a subset of disclosurerelated items. The majority of these disclosure related survey items were adapted from an existing survey tool designed to understand the factors influencing LGB youth's choice to disclose their sexual orientation in the healthcare setting. ${ }^{31}$ Additional items were adapted from surveys used to understand health system factors important to LGB youth ${ }^{32}$ and transgender adults' experiences accessing healthcare. ${ }^{26,33}$ To ensure the survey language was appropriate for transgender adolescents and young adults, items underwent cognitive interviewing with two transgender young adults prior to content validation by seven transgender health content experts. Additional survey items asked participants to select from a list of options regarding why they avoided telling a healthcare provider about their identity, strategies HCPs could enlist to help them feel more comfortable talking about their gender identity and how they would want a conversation about their gender identity to start.

Outcome variables.-Our two primary outcome variables were voluntary disclosure and intentional avoidance. Voluntary disclosure was defined as a yes response to the following question "Have you ever chosen to tell a HCP outside of the gender clinic about your gender identity?". Intentional avoidance was defined as a yes response to the following question "Have there been times you felt it could be important for your HCP to know your gender identity but you avoided telling them?".

Demographic characteristics.-Gender identity was operationalized based on responses to the following question "How do you describe your gender identity?" A range of 15 possible responses were provided as well as a free text option. For this analysis, we categorized responses into one of three categories 'transmasculine', 'transfeminine' and 
'nonbinary.' Participants who selected only 'transmasculine' or only 'transfeminine' were included in these two respective groups. The remaining 29 participants, who identified outside of these two binary categories were coded to the umbrella term 'nonbinary'. Of these 29 youth, 20 specifically selected the term 'nonbinary' to describe their identity. Of the remaining 9 participants, 3 selected the term 'genderqueer', 3 selected 'androgyne', 2 selected 'agender' and 1 selected 'demiboy'. Among additional demographic questions, we categorized age into younger than 18 versus 18 or older, due to the impact of age on access to care and parental consent. Race/ethnicity was self-identified, and grouped into one of two categories for this analysis: 'White', or 'Non-white' due to small numbers of respondents selecting races other than white. Travel distance to clinic was assessed using the question "How long did it take you to get to clinic today?" and responses were grouped into 'less than 30 minutes', '30 minutes to 1 hour' and 'more than 1 hour'. Lastly, participants indicated the clinic site at which they were receiving their care as either 'Endocrinology' or 'Adolescent Medicine'.

Gender-related characteristics.-In addition to self-described gender identity, the survey assessed other dimensions of gender presentation and the extent to which youth had discussed their gender identity with others. Gender expression was assessed using the following question " A person's appearance, style, dress, or the way they walk or talk may affect how people describe them. How do you think other people who don't know you would describe your appearance?'Responses were selected from a 5-point Likert scale. Youth responses were grouped into feminine ('very or mostly feminine' and 'somewhat feminine'), neutral, or masculine ('very or mostly masculine' and 'somewhat masculine'). To assess perception of passing, the following question was used: "Some people use the word passing to describe when most strangers perceive that they are the gender that they identify with. How well do you feel you pass as the gender you identify with?" and responses were recorded on a 4-point continuum from 'don't pass at all' to 'pass all of the time'. To assess the degree to which participants were out about their gender identity, the following question was used "Outside of healthcare, how out are you about your gender identity right now?" with a 5-point response continuum ranging from 'not out to anyone' to 'out to everyone.' The length of time out was assessed by asking how much time had passed since the first time participants disclosed their gender identity to someone else. Time out to parent was operationalized using the following question: "How long ago did you come out to your parent/guardian about your gender identity?." Responses to both time out and time out to parent were grouped into 'less than 1 year', ' 1 to 2 years', ' 2 to 3 years' and 'more than 3 years'. Finally, to assess each youth's most supportive parental relationship, parental support was assessed as a continuous variable based on responses to the following question "On a scale of 1 to 10, how supportive would you say your most supportive parent/legal guardian is of your transition? (1 being not supportive at all and 10 being extremely supportive)".

Factors influencing gender identity disclosure.-Two items were used to understand the clinic and provider level factors youth felt influenced their comfort with gender identity disclosure. Pre-determined response items were derived from existing survey measures assessing sexual orientation disclosure among LGB youth ${ }^{31}$ and prior studies exploring transgender youth's experiences accessing healthcare. ${ }^{32,34}$ 
Analyses

Descriptive statistics were used to report the prevalence of voluntary disclosure and intentional avoidance, as well as preferences for disclosure conversations and reasons for intentional avoidance. To identify factors associated with voluntary disclosure and intentional avoidance, we examined each of these two outcome variables separately. First, bivariate analyses were conducted using chi-square tests for categorical variables (or Fisher's exact test when expected cell sizes were $<5$ ) and t-tests for continuous variables to identify whether demographic and gender-related characteristics were associated with either of our outcomes. We then examined the association between demographic and genderrelated characteristics and each of our two primary outcome variables (voluntary disclosure and intentional avoidance) by running two separate logistic regression models for each outcome variable. The first model included only demographic variables and the second included demographic characteristics and any gender-related characteristics associated with the outcome at $\mathrm{p}<0.15$ in the bivariate analysis. For multivariable models, we considered statistical significance to be $p<0.05$. Finally, descriptive statistics were used to report youth perspectives on how to create more inclusive healthcare environments. Data analysis was conducted using Stata version 14.2 (StataCorps, College Station, TX).

Of the 204 participants, $75 \%$ had complete data for all outcome variables, demographic characteristics and gender-related characteristics creating an analytic sample of 153 participants which was used for both bivariate and regression analyses. The proportion of missingness was minimal for our two primary outcome variables voluntary disclosure $(0.4 \%)$ and intentional avoidance (1.5\%). Missingness of the independent variables was highest for parental support (8.8\%) and age (7.8\%). Because missingness was largest for our independent variables and nearly complete for both primary outcome variables, we chose not to impute missing data. However we did conduct a sensitivity analysis using the missing indicator method. ${ }^{35}$

\section{Results}

\section{Sample Characteristics}

Two-thirds (65\%) of youth in our sample identified as transmasculine, almost one-fifth transfeminine (16\%), and one-fifth nonbinary (19\%; Table 1$)$. The majority $(84 \%)$ were seen in Adolescent Medicine clinic for their gender care, and over half (57\%) were under the age of 18. Two-thirds (66\%) traveled longer than 30 minutes to clinic, and $88 \%$ identified their race/ethnicity as 'White'.

\section{Voluntary Disclosure}

The majority of youth (78\%) reported telling a HCP outside of gender clinic about their gender identity at some point in their lifetime. Youth reported varying preferences with respect to how they would like to see a conversation about their gender identity start. Nearly half $47 \%$ indicated they would prefer the provider initiate the conversation and only $25 \%$ indicated they would prefer to bring it up themselves (with remaining youth indicating that either it made no difference (17\%), that it depended on the situation (9\%), or that they were unsure (3\%)). Among those who preferred a provider-initiated discussion ( $\mathrm{n}=71), 55 \%$ 
indicated they would prefer that the provider initiate this discussion during the confidential portion of the provider visit.

When examining respondent factors bivariately associated with voluntary disclosure (Table 1), a perception of passing most of the time was associated with an increased likelihood of voluntary disclosure ( $91 \%$ vs. $50 \%, \mathrm{p}=0.003$ ). Additionally, prevalence of voluntary disclosure was higher in youth who were out to more people about their gender identity ( $89 \%$ vs. $33 \%, \mathrm{p}=0.001$ ), had been out for longer periods of time ( $82 \%$ vs. $36 \%, \mathrm{p}<0.0001$ ), and youth who were out to a parent for a longer period of time ( $86 \%$ vs. $63 \%, \mathrm{p}=0.048$ ). Voluntary disclosure was not associated with youth's race/ethnicity, travel distance, clinic site or perception of parental support in bivariate analysis.

In the first regression model (Table 2), participants who identified as transfeminine had $61 \%$ lower odds of voluntarily disclosing than participants who identified as transmasculine $(\mathrm{OR}=0.39$; 95\%CI: 0.13, 1.15), though this did not reach statistical significance. In the second regression model, participants who were out to few or no one had $88 \%$ lower odds of having voluntarily disclosed than those who were out to everyone $(\mathrm{OR}=0.12 ; 95 \% \mathrm{CI}$ : 0.02 , 0.81). Participants who had been out for less than 1 year (OR=0.03; 95\% CI: $0.004,0.31$ ) had $97 \%$ lower odds of having voluntarily disclosed compared to those who were out for 2-3 years. Additionally, participants who were 18 or older (OR=0.33; 95\% CI: $0.11,0.98)$ had $67 \%$ lower odds of voluntarily disclosure when compared to youth under 18 .

\section{Intentional Avoidance}

Almost half (46\%) of youth reported ever having intentionally avoided telling a healthcare provider about their gender identity when they thought it was important. Of those who indicated they had avoided ( $\mathrm{n}=70)$, the most common reasons for avoidance were 'I didn't feel comfortable talking about it' (66\%) and 'I didn't know how to bring it up' (65\%; Table $3)$.

In unadjusted analysis, intentional avoidance was associated with lower levels of parental support (7.6 vs. 8.1, $\mathrm{p}=0.008$ ) and having a gender expression that was neither feminine nor masculine ( $86 \%$ 'neither feminine nor masculine' versus 57\% 'equally masculine and feminine' versus $47 \%$ 'somewhat/very masculine' versus $21 \%$ 'somewhat/very feminine', $\mathrm{p}=0.008$ ). With the exception of clinic site, no association was found between intentional avoidance and other demographic variables or aspects of outness.

In the first regression model, participants seen in the endocrine-based gender clinic had 69\% lower odds of having intentionally avoided ( $\mathrm{OR}=0.31 ; 95 \% \mathrm{CI}: 0.11,0.89$ ) compared to those seen in the adolescent medicine-based gender clinic. In the second regression model, youth with higher perceived parental support had 17\% lower odds of intentional avoidance $(\mathrm{OR}=0.83 ; 95 \%$ CI: $0.70-0.98)$.

In our sensitivity analyses using the missing indicator method, all of the significant findings from the first and second models remained significant with similar effect sizes and directions (data not shown). 


\section{Increasing Comfort with Voluntary Disclosure}

One-third of youth surveyed (34\%) indicated that they had both voluntarily disclosed and internationally avoided. When asked how settings outside of gender clinics can make youth more comfortable voluntarily disclosing their gender identity, the most commonly selected strategies were using their name and pronouns in the waiting room (85\%), using forms that allow them to list their name/pronouns (81\%) and gender identity (76\%), and educating front desk staff members about the importance of using the correct name and pronouns (79\%; Table 3). These were far more prevalent selections than ensuring gender identity would not be disclosed to their parents (11\%) or would not be documented in the electronic health record $(9 \%)$.

\section{Discussion}

To our knowledge, this is the first study investigating the health systems factors influencing transgender youth's comfort with gender identity disclosure. Our findings indicate that a majority of transgender youth have voluntarily disclosed their gender identity to a healthcare provider outside of a multidisciplinary gender clinic, yet nearly a quarter reported they had never done so. Additionally, almost half of youth in our study had intentionally avoided disclosing when they felt it was important, highlighting the need to create more inclusive spaces for transgender youth in the healthcare setting. We suspect that transgender youth who are not yet receiving care in a multidisciplinary gender clinic may experience greater reluctance to disclosing their gender identity in health care settings due to the same barriers (personal, family or system) that have interfered with their ability to access care in the gender clinic. For this reason, voluntary disclosure in our sample is likely higher than might be found in a broader population of transgender youth. Despite this, our results remain notable for three reasons. First, these results offer a valuable estimate of voluntary disclosure and intentional avoidance. Even though we note above that the estimates may be more positive than the general population of transgender youth, these findings alone indicate nearly a quarter of youth refrained from ever voluntarily disclosing their gender identity in healthcare settings outside of gender clinic. This number alone is sobering, but is likely an underestimate of the true prevalence in a non-clinical sample.

Second, these data illuminate that there are important patient characteristics that may inform a more tailored discussion about how to improve comfort in healthcare settings for the most vulnerable subsets of the transgender youth. Youth older than 18 and those who were less out about their identities were less likely to have ever voluntarily disclosed, a finding likely due at least in part to the fact that this older group included youth presenting to care with limited parental support. These data highlight the need to recognize the heterogeneity of this patient population and importance of developing targeted strategies that embrace the intersectional nature of individual identities and experiences in both clinical care and research. ${ }^{36,37}$ Clinically, as we work to create welcoming healthcare environments we must recognize the uniqueness of each individuals' experience and include visual representations of youth with a wide range of ages, gender identities and gender expressions. With respect to research, future transgender health studies may benefit from continued assessment of 
additional dimensions of gender-related characteristics, such as gender expression, outness and passing.

Finally, these data highlight specific opportunities for health system interventions to improve access to care. The two primary reasons youth cited for intentional avoidance were related to discomfort initiating a conversation about gender identity during a clinical encounter. This aligns with Meckler's ${ }^{31}$ work investigating sexual orientation disclosure in LGB youth that found youth were far more comfortable disclosing their sexual orientation if their provider 'just asked' them about their identity. However, transgender youth in our study were far more likely to have indicated they avoided disclosure out of concern their HCP would not approve. Transgender youth in our study were also more likely to select strategies to increase comfort with disclosure like forms, LGBT affirming visual cues and positive waiting room experiences. ${ }^{31,32}$ Additionally, factors which LGB youth indicated were important to them in facilitating disclosure, like ensuring confidentiality, were much less important to our population of transgender youth. Finally, protective factors like parental support play a significant role in mitigating intentional avoidance and likely help facilitate access to gender affirming care, suggesting providers caring for transgender youth should consider opportunities to assist parents in supporting their transgender children. Our findings provide HCPs and health-system leadership with clear recommendations regarding strategies to make healthcare spaces safer for transgender youth to voluntarily disclose their gender identities.

The following limitations should be considered in interpreting the findings from this study. First, the study involves a convenience sample of transgender youth receiving care at a multidisciplinary gender clinic in one mid-sized city and lacked racial/ethnic diversity. Additionally, roughly a quarter of youth were excluded from our main analysis due to missing data; however these were included in our sensitivity analysis with similar results. Our findings must be interpreted narrowly as participants in this study have already overcome significant barriers to accessing care, and because of this, may differ in many aspects from individuals in a broader sample of transgender youth not currently accessing care. An investigation of disclosure in a broader sample of transgender youth is warranted to investigate experiences in populations not represented in our sample. Third, given the cross-sectional nature of the study, the results are subject to recall bias. In addition, the temporality with which disclosure or avoidance occurred with respect to presentation to the gender clinic was unable to be assessed. Finally, because our primary outcome variables were assessed as having "ever" disclosed or "ever" avoided, our results do not quantify the frequency with which these occurred.

\section{Conclusion}

Approximately three-quarters of transgender youth in our study reported ever having voluntarily disclosed their gender identity to a healthcare provider outside of gender clinic, but almost half reported having ever intentionally avoided disclosure when they felt it was important. Youth who were over 18 and less out about their identities were less likely to have voluntarily disclosed. Participants who reported higher perceived parental support were less likely to have intentionally avoided highlighting the protective role parental support may 
play in mitigating avoidance and facilitating access to care. Youth selected several health systems level strategies to increase comfort with disclosure, suggesting a continued need to facilitate change at the level of the health system to create affirming environments and mitigate health disparities.

\title{
Acknowledgments:
}

This work was funded by the following training grants: T32 HD71834-5 (PI:Dermody) and T32 HD087162 (PI: Miller). This research was also supported by the National Center for Advancing Translational Sciences and the National Institute on Alcohol Abuse and Alcoholism (TL1TR001858 and K01AA027564 to RWSC through the University of Pittsburgh). This work was presented at the 2019 Society for Adolescent Health and Medicine (SAHM) national meeting.

The content is solely the responsibility of the authors and does not necessarily represent the official views of the NIH. The NIH was not involved in this article's study design, analysis or interpretation of data, the writing of the report, or the decision to submit the article for publication.

\author{
Abbreviations: \\ HCP \\ healthcare provider \\ LGB \\ lesbian, gay, bisexual \\ IRB \\ Institutional Review Board
}

\section{References}

1. Gridley SJ, Crouch JM, Evans Y, et al. Youth and Caregiver Perspectives on Barriers to GenderAffirming Health Care for Transgender Youth. The Journal of adolescent health : official publication of the Society for Adolescent Medicine. 2016;59(3):254-261. [PubMed: 27235374]

2. Safer JD, Coleman E, Feldman J, et al. Barriers to healthcare for transgender individuals. Current opinion in endocrinology, diabetes, and obesity. 2016;23(2):168-171.

3. Fisher CB, Fried AL, Desmond M, Macapagal K, Mustanski B. Perceived Barriers to HIV Prevention Services for Transgender Youth. LGBT health. 2018;5(6):350-358. [PubMed: 30070960]

4. Macapagal K, Bhatia R, Greene GJ. Differences in Healthcare Access, Use, and Experiences Within a Community Sample of Racially Diverse Lesbian, Gay, Bisexual, Transgender, and Questioning Emerging Adults. LGBT health. 2016;3(6):434-442. [PubMed: 27726496]

5. Garofalo R, Deleon J, Osmer E, Doll M, Harper GW. Overlooked, misunderstood and at-risk: exploring the lives and HIV risk of ethnic minority male-to-female transgender youth. The Journal of adolescent health : official publication of the Society for Adolescent Medicine. 2006;38(3):230236. [PubMed: 16488820]

6. Connolly MD, Zervos MJ, Barone CJ 2nd, Johnson CC, Joseph CL The Mental Health of Transgender Youth: Advances in Understanding. The Journal of adolescent health : official publication of the Society for Adolescent Medicine. 2016;59(5):489-495. [PubMed: 27544457]

7. Daniel H, Butkus R. Lesbian, Gay, Bisexual, and Transgender Health Disparities: Executive Summary of a Policy Position Paper From the American College of Physicians. Annals of internal medicine. 2015;163(2):135-137. [PubMed: 25961598]

8. Veale JF, Watson RJ, Peter T, Saewyc EM. Mental Health Disparities Among Canadian Transgender Youth. The Journal of adolescent health : official publication of the Society for Adolescent Medicine. 2017;60(1):44-49. [PubMed: 28007056]

9. Day JK, Fish JN, Perez-Brumer A, Hatzenbuehler ML, Russell ST. Transgender Youth Substance Use Disparities: Results From a Population-Based Sample. The Journal of adolescent health : official publication of the Society for Adolescent Medicine. 2017;61(6):729-735. [PubMed: 28942238] 
10. Olson J, Schrager SM, Belzer M, Simons LK, Clark LF. Baseline Physiologic and Psychosocial Characteristics of Transgender Youth Seeking Care for Gender Dysphoria. The Journal of adolescent health : official publication of the Society for Adolescent Medicine. 2015;57(4):374380. [PubMed: 26208863]

11. Reisner SL, Biello KB, Hughto JMW, et al. Psychiatric diagnoses and comorbidities in a diverse, multicity cohort of young transgender women: baseline findings from project LifeSkills. JAMA pediatrics. 2016;170(5):481-486. [PubMed: 26999485]

12. De Pedro KT, Gilreath TD, Jackson C, Esqueda MC. Substance Use Among Transgender Students in California Public Middle and High Schools. The Journal of school health. 2017;87(5):303-309. [PubMed: 28382667]

13. Rider GN, McMorris BJ, Gower AL, Coleman E, Eisenberg ME. Health and Care Utilization of Transgender and Gender Nonconforming Youth: A Population-Based Study. Pediatrics. 2018;141(3).

14. Whitehead J, Shaver J, Stephenson R. Outness, Stigma, and Primary Health Care Utilization among Rural LGBT Populations. PloS one. 2016;11(1):e0146139.

15. Durwood L, McLaughlin KA, Olson KR. Mental Health and Self-Worth in Socially Transitioned Transgender Youth. Journal of the American Academy of Child and Adolescent Psychiatry. 2017;56(2):116-123.e112.

16. Olson KR, Durwood L, DeMeules M, McLaughlin KA. Mental Health of Transgender Children Who Are Supported in Their Identities. Pediatrics. 2016;137(3):e20153223.

17. Colizzi M, Costa R, Todarello O. Transsexual patients' psychiatric comorbidity and positive effect of cross-sex hormonal treatment on mental health: results from a longitudinal study. Psychoneuroendocrinology. 2014;39:65-73. [PubMed: 24275005]

18. de Vries AL, McGuire JK, Steensma TD, Wagenaar EC, Doreleijers TA, Cohen-Kettenis PT. Young adult psychological outcome after puberty suppression and gender reassignment. Pediatrics. 2014;134(4):696-704. [PubMed: 25201798]

19. Dhejne C, Van Vlerken R, Heylens G, Arcelus J. Mental health and gender dysphoria: A review of the literature. International review of psychiatry. 2016;28(1):44-57. [PubMed: 26835611]

20. Dowshen N, Lee S, Franklin J, Castillo M, Barg F. Access to Medical and Mental Health Services Across the HIV Care Continuum Among Young Transgender Women: A Qualitative Study. Transgender health. 2017;2(1):81-90. [PubMed: 28861551]

21. Dowshen N, Meadows R, Byrnes M, Hawkins L, Eder J, Noonan K. Policy Perspective: Ensuring Comprehensive Care and Support for Gender Nonconforming Children and Adolescents. Transgender health. 2016;1(1):75-85. [PubMed: 28861528]

22. Korpaisarn S, Safer JD. Gaps in transgender medical education among healthcare providers: A major barrier to care for transgender persons. Reviews in endocrine \& metabolic disorders. 2018.

23. Quinn GP, Sutton SK, Winfield B, et al. Lesbian, Gay, Bisexual, Transgender, Queer/Questioning (LGBTQ) Perceptions and Health Care Experiences. Journal of gay \& lesbian social services. 2015;27(2):246-261. [PubMed: 30996583]

24. Cruz TM. Assessing access to care for transgender and gender nonconforming people: a consideration of diversity in combating discrimination. Social science \& medicine (1982). 2014;110:65-73. [PubMed: 24727533]

25. Maragh-Bass AC, Torain M, Adler R, et al. Is It Okay To Ask: Transgender Patient Perspectives on Sexual Orientation and Gender Identity Collection in Healthcare. Academic Emergency Medicine. 2017;24(6):655-667. [PubMed: 28235242]

26. James SE, Herman JL, Rankin S, Keisling M, Mottet L, \& Anafi M . The Report of the 2015 U.S. Transgender Survey. . Washington, DC: National Center for Transgender Equality;2016.

27. Samuels EA, Tape C, Garber N, Bowman S, Choo EK. "Sometimes You Feel Like the Freak Show": A Qualitative Assessment of Emergency Care Experiences Among Transgender and Gender-Nonconforming Patients. Annals of emergency medicine. 2018;71(2):170182.e171.

28. Rossman K, Salamanca P, Macapagal K. A Qualitative Study Examining Young Adults' Experiences of Disclosure and Nondisclosure of LGBTQ Identity to Health Care Providers. Journal of homosexuality. 2017;64(10):1390-1410. [PubMed: 28459379] 
29. Kamen CS, Smith-Stoner M, Heckler CE, Flannery M, Margolies L. Social support, self-rated health, and lesbian, gay, bisexual, and transgender identity disclosure to cancer care providers. Oncology nursing forum. 2015;42(1):44-51. [PubMed: 25542320]

30. Metcalfe R, Laird G, Nandwani R. Don't ask, sometimes tell. A survey of men who have sex with men sexual orientation disclosure in general practice. International journal of STD \& AIDS. 2015;26(14):1028-1034. [PubMed: 25527656]

31. Meckler GD, Elliott MN, Kanouse DE, Beals KP, Schuster MA. Nondisclosure of sexual orientation to a physician among a sample of gay, lesbian, and bisexual youth. Archives of pediatrics \& adolescent medicine. 2006;160(12):1248-1254. [PubMed: 17146022]

32. Hoffman ND, Freeman K, Swann S. Healthcare preferences of lesbian, gay, bisexual, transgender and questioning youth. Journal of Adolescent Health. 2009;45(3):222-229.

33. Kosenko K, Rintamaki L, Raney S, Maness K. Transgender patient perceptions of stigma in health care contexts. Medical care. 2013;51(9):819-822. [PubMed: 23929399]

34. Guss CE, Woolverton GA, Borus J, Austin SB, Reisner SL, Katz-Wise SL. Transgender Adolescents' Experiences in Primary Care: A Qualitative Study. The Journal of adolescent health : official publication of the Society for Adolescent Medicine. 2019;65(3):344-349. [PubMed: 31227384]

35. Horton NJ, Kleinman KP. Much ado about nothing: A comparison of missing data methods and software to fit incomplete data regression models. The American statistician. 2007;61(1):79-90. [PubMed: 17401454]

36. Kamen CS, Alpert A, Margolies L, et al. "Treat us with dignity": a qualitative study of the experiences and recommendations of lesbian, gay, bisexual, transgender, and queer (LGBTQ) patients with cancer. Supportive care in cancer : official journal of the Multinational Association of Supportive Care in Cancer. 2018.

37. Thompson HM. Patient Perspectives on Gender Identity Data Collection in Electronic Health Records: An Analysis of Disclosure, Privacy, and Access to Care. Transgender health. 2016;1(1):205-215. [PubMed: 28861535] 


\section{Implications and Contribution:}

This study highlights the importance of developing strategies to embrace the intersectional nature of individual identities and experiences. Future research may benefit from assessing gender-related characteristics like outness and parental support. To mitigate intentional avoidance, providers can develop opportunities for parents to learn how to support their transgender children. 


\section{Table 1}

Bivariate Analysis of Factors Associated with Gender Identity Disclosure and Avoidance ( $\mathrm{n}=153)$

\begin{tabular}{|c|c|c|c|c|c|}
\hline & \multirow{2}{*}{$\begin{array}{c}\text { Overall sample } \\
n\left(\%^{a}\right)\end{array}$} & \multicolumn{2}{|c|}{$\begin{array}{l}\text { Prevalence of Voluntary Disclosure } \\
\text { Outside of Gender Clinic }\end{array}$} & \multicolumn{2}{|c|}{$\begin{array}{l}\text { Prevalence of Intentional } \\
\text { Avoidance of Gender Identity } \\
\text { Disclosure Outside of Gender } \\
\text { Clinic }\end{array}$} \\
\hline & & $n\left(\%^{b}\right)$ & $p$ & $n\left(\%^{b}\right)$ & $p$ \\
\hline \multicolumn{6}{|c|}{ Demographic characteristics } \\
\hline \multicolumn{6}{|l|}{ Gender identity } \\
\hline Transmasculine & $100(65)$ & $83(83)$ & 0.101 & $50(50)$ & 0.084 \\
\hline Transfeminine & $24(16)$ & $16(67)$ & & $6(25)$ & \\
\hline Nonbinary & $29(19)$ & $20(69)$ & & $14(48)$ & \\
\hline \multicolumn{6}{|l|}{ Age } \\
\hline$<18$ years & $87(57)$ & $71(82)$ & 0.191 & $37(43)$ & 0.358 \\
\hline$\geq 18$ years & $66(43)$ & $48(73)$ & & $33(50)$ & \\
\hline \multicolumn{6}{|l|}{ Race } \\
\hline White & $135(88)$ & $104(77)$ & 0.546 & $61(45)$ & 0.700 \\
\hline Non-white & $18(12)$ & $15(83)$ & & $9(50)$ & \\
\hline \multicolumn{6}{|l|}{ Travel distance } \\
\hline$<30$ minutes & $53(35)$ & $38(72)$ & 0.112 & $26(49)$ & 0.809 \\
\hline 30 minutes-1hour & $56(37)$ & $42(75)$ & & $24(43)$ & \\
\hline$>1$ hour & $44(29)$ & $39(89)$ & & $20(45)$ & \\
\hline \multicolumn{6}{|l|}{ Clinic site } \\
\hline Adolescent Medicine & $128(84)$ & $97(76)$ & 0.179 & $64(50)$ & 0.017 \\
\hline Endocrinology & $25(16)$ & $22(88)$ & & $6(24)$ & \\
\hline \multicolumn{6}{|c|}{ Gender-related characteristics (GRC) } \\
\hline \multicolumn{6}{|l|}{ Outness } \\
\hline Out to everyone & $66(43)$ & $59(89)$ & 0.001 & $30(45)$ & 0.699 \\
\hline Out to most & $55(36)$ & $42(76)$ & & $23(42)$ & \\
\hline Out to some & $23(15)$ & $15(65)$ & & $13(57)$ & \\
\hline Out to few/none & $9(6)$ & $3(33)$ & & $4(44)$ & \\
\hline \multicolumn{6}{|c|}{$\begin{array}{l}\text { Time since first gender identity } \\
\text { disclosure to anyone }\end{array}$} \\
\hline$<1$ year & $14(9)$ & $5(36)$ & $<0.0001$ & $8(57)$ & 0.211 \\
\hline $1-2$ years & $28(18)$ & $19(68)$ & & $8(29)$ & \\
\hline $2-3$ years & $54(35)$ & $48(89)$ & & $27(50)$ & \\
\hline$>3$ years & $57(37)$ & $47(82)$ & & $27(47)$ & \\
\hline \multicolumn{6}{|c|}{$\begin{array}{l}\text { Time since first gender identity } \\
\text { disclosure to parent }\end{array}$} \\
\hline$<1$ year & $32(21)$ & $20(63)$ & 0.048 & $15(47)$ & 0.789 \\
\hline $1-2$ years & $37(24)$ & $27(73)$ & & $16(43)$ & \\
\hline $2-3$ years & $47(31)$ & $40(85)$ & & $24(51)$ & \\
\hline$>3$ years & $37(24)$ & $32(86)$ & & $15(41)$ & \\
\hline
\end{tabular}

Perceived passing as gender 


\begin{tabular}{|c|c|c|c|c|c|}
\hline & \multirow{2}{*}{$\begin{array}{l}\text { Overall sample } \\
\quad n\left(\%{ }^{a}\right)\end{array}$} & \multicolumn{2}{|c|}{$\begin{array}{l}\text { Prevalence of Voluntary Disclosure } \\
\text { Outside of Gender Clinic }\end{array}$} & \multicolumn{2}{|c|}{$\begin{array}{l}\text { Prevalence of Intentional } \\
\text { Avoidance of Gender Identity } \\
\text { Disclosure Outside of Gender } \\
\text { Clinic }\end{array}$} \\
\hline & & $n\left(\%^{b}\right)$ & $p$ & $n\left(\%^{b}\right)$ & $p$ \\
\hline Pass all of the time & $34(22)$ & $29(85)$ & 0.003 & $11(32)$ & 0.117 \\
\hline Pass most of the time & $45(29)$ & $41(91)$ & & $24(53)$ & \\
\hline Pass some of the time & $64(42)$ & $44(69)$ & & $28(44)$ & \\
\hline Dont pass at all & $10(7)$ & $5(50)$ & & $7(70)$ & \\
\hline \multicolumn{6}{|l|}{ Gender Expression } \\
\hline Masculine & $108(71)$ & $85(79)$ & 0.812 & $51(47)$ & 0.008 \\
\hline Feminine & $24(16)$ & $19(79)$ & & $5(21)$ & \\
\hline Equally feminine/masculine & $14(9)$ & $10(71)$ & & $8(57)$ & \\
\hline Neither feminine/masculine & $7(5)$ & $5(71)$ & & $6(86)$ & \\
\hline Parental support, mean(SD) & $8.13(2.31)$ & $8.25(2.13)$ & 0.250 & $7.60(2.45)$ & 0.008 \\
\hline
\end{tabular}

${ }^{a=}$ column percentage

$b=$

$=$ row percentage, $\mathrm{OR}=$ odds ratio, $\mathrm{CI}=$ confidence interval, $\mathrm{SD}=$ standard deviation, passing was defined as when most strangers perceive you as the gender you identify with 


\section{Table 2}

Factors Associated with Gender Identity Disclosure and Avoidance of Disclosure

\begin{tabular}{|c|c|c|c|c|}
\hline & \multicolumn{2}{|c|}{$\frac{\text { Voluntary Disclosure Outside of Gender }}{\underline{\text { Clinic }}}$} & \multicolumn{2}{|c|}{$\frac{\text { Avoidance of Gender Identity Disclosure }}{\text { Outside of Gender clinic }}$} \\
\hline & $\begin{array}{c}\text { Model 1 } \\
\text { OR }(95 \% \text { CI })\end{array}$ & $\begin{array}{c}\text { Model 2 } \\
\text { OR }(95 \% \text { CI })\end{array}$ & $\begin{array}{c}\text { Model 1 } \\
\text { OR }(95 \% \text { CI })\end{array}$ & $\begin{array}{c}\text { Model 2 } \\
\text { OR }(95 \% \text { CI })\end{array}$ \\
\hline \multicolumn{5}{|c|}{ Demographic characteristics } \\
\hline \multicolumn{5}{|l|}{ Gender identity } \\
\hline Transmasculine & 1.00 (referent) & 1.00 (referent) & 1.00 (referent) & 1.00 (referent) \\
\hline Transfeminine & $0.39(0.13-1.15)^{\dagger}$ & $1.05(0.24-4.56)$ & $0.35(0.12-1.02)^{\dagger}$ & $0.39(0.08-1.89)$ \\
\hline Nonbinary & $0.53(0.19-1.47)$ & $0.76(0.20-2.93)$ & $0.91(0.37-2.24)$ & $0.77(0.25-2.38)$ \\
\hline \multicolumn{5}{|l|}{ Age } \\
\hline$<18$ years & 1.00 (referent) & 1.00 (referent) & 1.00 (referent) & 1.00 (referent) \\
\hline$\geq 18$ years & $0.72(0.31-1.66)$ & $0.33(0.11-0.98)^{*}$ & $1.64(0.81-3.32)$ & $1.54(0.72-3.30)$ \\
\hline \multicolumn{5}{|l|}{ Race } \\
\hline White & 1.00 (referent) & 1.00 (referent) & 1.00 (referent) & 1.00 (referent) \\
\hline Non-white & $1.12(0.28-4.42)$ & $1.21(0.24-6.10)$ & $1.29(0.45-3.64)$ & $1.41(0.48-4.15)$ \\
\hline \multicolumn{5}{|l|}{ Travel distance } \\
\hline$<30$ minutes & $0.92(0.36-2.35)$ & $1.04(0.32-3.42)$ & $0.89(0.39-2.04)$ & $0.86(0.36-2.05)$ \\
\hline 30minutes-1hour & 1.00 (referent) & 1.00 (referent) & 1.00 (referent) & 1.00 (referent) \\
\hline$>1$ hour & $2.23(0.72-6.99)$ & $2.23(0.53-9.44)$ & $1.02(0.44-2.36)$ & $0.85(0.38-2.14)$ \\
\hline \multicolumn{5}{|l|}{ Clinic site } \\
\hline Adolescent Medicine & 1.00 (referent) & 1.00 (referent) & 1.00 (referent) & 1.00 (referent) \\
\hline Endocrinology & $2.63(0.69-10.04)$ & $3.89(0.70-21.48)$ & $0.31(0.11-0.89)^{*}$ & $0.44(0.15-1.33)$ \\
\hline \multicolumn{5}{|c|}{ Gender-related characteristics (GRC) } \\
\hline \multicolumn{5}{|l|}{ Outness } \\
\hline Out to everyone & & 1.00 (referent) & & \\
\hline Out to most & & $0.53(0.17-1.63)$ & & \\
\hline Out to some & & $0.27(0.06-1.14)$ & & \\
\hline Out to few/none & & $0.12(0.02-0.81)^{*}$ & & \\
\hline \multicolumn{5}{|c|}{$\begin{array}{l}\text { Time since first gender identity } \\
\text { disclosure to anyone }\end{array}$} \\
\hline$<1$ years & & $0.03(0.004-0.31)^{* *}$ & & \\
\hline $1-2$ years & & $0.32(0.06-1.75)$ & & \\
\hline 2-3 years & & 1.00 (referent) & & \\
\hline$>3$ years & & $0.77(0.20-2.91)$ & & \\
\hline \multicolumn{5}{|c|}{$\begin{array}{l}\text { Time since first gender identity } \\
\text { disclosure to parent }\end{array}$} \\
\hline$<1 \mathrm{yr}$ & & $3.17(0.46-21.72)$ & & \\
\hline $1-2$ years & & $1.15(0.24-5.44)$ & & \\
\hline $2-3$ years & & 1.00 (referent) & & \\
\hline$>3$ years & & $1.75(0.36-8.48)$ & & \\
\hline
\end{tabular}




\begin{tabular}{|c|c|c|c|c|}
\hline & \multicolumn{2}{|c|}{$\frac{\text { Voluntary Disclosure Outside of Gender }}{\text { Clinic }}$} & \multicolumn{2}{|c|}{$\begin{array}{l}\text { Avoidance of Gender Identity Disclosure } \\
\text { Outside of Gender clinic }\end{array}$} \\
\hline & Model 1 & Model 2 & Model 1 & Model 2 \\
\hline & OR $(95 \% \mathrm{CI})$ & OR $(95 \% \mathrm{CI})$ & OR $(95 \% \mathrm{CI})$ & OR $(95 \% \mathrm{CI})$ \\
\hline \multicolumn{5}{|l|}{ Perceived passing as gender } \\
\hline Pass all the time & & $1.66(0.42-6.55)$ & & $1.05(0.36-3.00)$ \\
\hline Pass most of the time & & $4.34(1.07-17.65)$ & & $1.72(0.72-4.12)$ \\
\hline Pass some of the time & & 1.00 (referent) & & 1.00 (referent) \\
\hline Don't pass at all & & $0.50(0.08-3.30)$ & & $2.55(0.51-12.84)$ \\
\hline \multicolumn{5}{|l|}{ Gender Expression } \\
\hline Masculine & & & & 1.00 (referent) \\
\hline Feminine & & & & $0.60(0.14-2.61)$ \\
\hline Equally feminine/masculine & & & & $1.79(0.43-7.38)$ \\
\hline Neither feminine/masculine & & & & $6.61(0.67-65.43)$ \\
\hline Parental support, mean(SD) & & & & $0.83(0.70-0.98) *$ \\
\hline
\end{tabular}

$\mathrm{SD}=$ standard deviation, passing was defined as when most strangers perceive you as the gender you identify with

Model 1: demographics only; Model 2: demographics + GRC's significant $\mathrm{p}<0.15$ in bivariate analysis

$t_{\mathrm{p}}<0.10$

p $<0.05$

*** $\mathrm{p}<0.01$ 


\section{Table 3}

Youth Reported Factors that Influence Gender Identity Disclosure

What are some of the reasons you have avoided telling your health care provider about your gender identity?
\% indicated this respons
I didnt' feel comfortable talking about it
I didnt know how to bring up
The healthcare provider never asked me
I didnt think the healthcare provider would approve
I was worried about how office staff might react
I was worried about being denied services
My parent/guardian was in the room
I was scared the healthcare provider would tell parent
I didnt think it was important
I was worried about potential danger or harm

What can healthcare providers outside of the gender clinic do to make you feel more comfortable talking about your gender identity? $\%$ indicated this response

\begin{tabular}{l|l} 
Use my name and pronouns in waiting room & 85 \\
Use forms that allow me to list my name/pronouns & 81 \\
Educate front desk staff about the importance of using name/pronouns & 79 \\
Use forms that allow me to list my gender identity & 76 \\
Put LGBT-friendly materials in the waiting room & 66 \\
Talk to me without my parents in the room & 36 \\
Ask if I would like to talk about my gender identity during routine visits & 31 \\
Assure me my healthcare provider will not tell parents & 11 \\
Assure me my healthcare provider will not write in my chart & 9
\end{tabular}

LGBT= lesbian, gay, bisexual and transgender 